ARTICLE

Received 2 Jan 2015 | Accepted 24 Jun 2015 | Published 3 Aug 2015

DOI: $10.1038 /$ ncomms 8898

OPEN

\title{
Unlocking the energy capabilities of micron-sized $\mathrm{LiFePO}_{4}$
}

Limin Guo ${ }^{1,2}$, Yelong Zhang ${ }^{1,2}$, Jiawei Wang ${ }^{1}$, Lipo Ma1, Shunchao Ma1,2, Yantao Zhang ${ }^{1,2}$, Erkang Wang ${ }^{1}$, Yujing $\mathrm{Bi}^{3}$, Deyu Wang ${ }^{3}$, William C. McKee ${ }^{4}, \mathrm{Ye} \mathrm{Xu}^{4}$, Jitao Chen ${ }^{5}$, Qinghua Zhang ${ }^{6}$, Cewen Nan ${ }^{6}$, Lin $\mathrm{Gu}^{7}$, Peter G. Bruce ${ }^{8} \&$ Zhangquan Peng ${ }^{1}$

Utilization of $\mathrm{LiFePO}_{4}$ as a cathode material for $\mathrm{Li}$-ion batteries often requires size nanonization coupled with calcination-based carbon coating to improve its electrochemical performance, which, however, is usually at the expense of tap density and may be environmentally problematic. Here we report the utilization of micron-sized $\mathrm{LiFePO}_{4}$, which has a higher tap density than its nano-sized siblings, by forming a conducting polymer coating on its surface with a greener diazonium chemistry. Specifically, micron-sized $\mathrm{LiFePO}_{4}$ particles have been uniformly coated with a thin polyphenylene film via the spontaneous reaction between $\mathrm{LiFePO}_{4}$ and an aromatic diazonium salt of benzenediazonium tetrafluoroborate. The coated micron-sized $\mathrm{LiFePO}_{4}$, compared with its pristine counterpart, has shown improved electrical conductivity, high rate capability and excellent cyclability when used as a 'carbon additive free' cathode material for rechargeable Li-ion batteries. The bonding mechanism of polyphenylene to $\mathrm{LiFePO}_{4} / \mathrm{FePO}_{4}$ has been understood with density functional theory calculations.

\footnotetext{
${ }^{1}$ State Key Laboratory of Electroanalytical Chemistry, Changchun Institute of Applied Chemistry, Chinese Academy of Sciences, Changchun, Jilin 130022, China. ${ }^{2}$ University of Chinese Academy of Sciences, Beijing 100049, China. ${ }^{3}$ Ningbo Institute of Materials Technology and Engineering, Chinese Academy of science, Ningbo, Zhejiang 315201, China. ${ }^{4}$ Department of Chemical Engineering, Louisiana State University, Baton Rouge, Louisiana 70803, USA. ${ }^{5}$ Beijing National Laboratory for Molecular Sciences, College of Chemistry and Molecular Engineering, Peking University, Beijing 100871, China. ${ }^{6}$ School of Materials Science and Engineering, State Key Lab of New Ceramics and Fine Processing, Tsinghua University, Beijing 100084, P.R. China. ${ }^{7}$ Beijing National Laboratory for Condensed Matter Physics, Institute of Physics, Chinese Academy of Sciences, Beijing 100190 China. ${ }^{8}$ Departments of Materials and Chemistry, University of Oxford, Parks Road, Oxford OX13PH UK. Correspondence and requests for materials should be addressed to E.W. (email: ekwang@ciac.ac.cn) or to P.G.B. (email: peter.bruce@materials.ox.ac.uk) or to Z.P. (email: zqpeng@ciac.ac.cn).
} 
i-ion battery, since its first commercialization in 1991, has drastically transformed and popularized portable electronic devices, and will continue to play a major role in the electrification of road transportation in the future ${ }^{1}$. However, for the realization of the latter, better energy storage materials are needed ${ }^{1-13} \cdot \mathrm{LiFePO}_{4}$, an environmentally benign and relatively safe cathode material for rechargeable Li-ion batteries, has attracted a great deal of interest during the last few decades ${ }^{2-4}$. Considerable efforts have been devoted to overcoming the intrinsically low electrical conductivity of $\mathrm{LiFePO}_{4}$, a drawback that hinders its direct use in Li-ion cells ${ }^{5,6}$. Several strategies, such as doping with foreign metal ions, have been explored ${ }^{7-9}$. However, the most common approach remains coating with carbon ${ }^{8}$. Carbon coatings are usually formed during $\mathrm{LiFePO}_{4}$ synthesis, in which an organic precursor (the carbon source) and the inorganic raw materials are mixed together. The subsequent calcination of the mixture in an inert or reducing atmosphere produces conducting carbon and $\mathrm{LiFePO}_{4}$, simultaneously ${ }^{10-12}$. Similarly, carbon coatings can also be introduced after $\mathrm{LiFePO}_{4}$ synthesis, in which an organic precursor and preformed $\mathrm{LiFePO}_{4}$ are mixed and then calcined ${ }^{13,14}$. The calcination-based strategies are often energy intensive and can be environmentally unfriendly because of the emission of harmful volatile organic compounds from the thermal decomposition of organic precursors ${ }^{15}$. Moreover, carbon coatings on $\mathrm{LiFePO}_{4}$ produced by heat treatment tend to be irregular, which does not provide a good connectivity for the particles and hence the expected performance for battery applications ${ }^{16}$. To mitigate the negative environmental effects of calcination, conducting polymers have been employed to increase the electronic conductivity and thus improve the performance of $\mathrm{LiFePO}_{4}$ (refs 17-22). Several methods have been used to produce polymer/ $/ \mathrm{LiFePO}_{4}$ composites, including electrochemical $^{19}$ and chemical ${ }^{20}$ polymerization in the presence of $\mathrm{LiFePO}_{4}$ particles; rapid mixing of conducting polymer colloidal and $\mathrm{LiFePO}_{4}$ suspensions ${ }^{21}$; and more recent spontaneous polymerization driven by the oxidation power of partially delithiated $\mathrm{LiFePO}_{4}$ (ref. 22).

It shall be noted here that the above mentioned carbon and conducting polymer-coating procedures work well mainly on nano-sized $\mathrm{LiFePO}_{4}$, ranging typically from 200 to $20 \mathrm{~nm}$ (ref. 3). The reason for using nano-sized $\mathrm{LiFePO}_{4}$ lies in that reducing particle size can shorten the solid-state diffusion distance within $\mathrm{LiFePO}_{4}$, which is beneficial to the high-power (or high rate) applications ${ }^{23}$. However, one obvious drawback associated with nano-sized $\mathrm{LiFePO}_{4}$ is the decreased tap density (and the resultant lower volumetric energy density), which becomes critical when fitting $\mathrm{LiFePO}_{4}$-based batteries into the trunks of pure electric vehicles ${ }^{3,4}$. Although the literatures on $\mathrm{LiFePO}_{4}$ are predominantly based on nano-sized materials, there are indeed some efforts of exploring submicron- and micron-sized $\mathrm{LiFePO}_{4}$. For instance, Dominiko et al. ${ }^{24}$ showed that a $0.5-\mu \mathrm{m}$ carbon-free $\mathrm{LiFePO}_{4}$ has a specific capacity of $72 \mathrm{mAhg}^{-1}$ at $1 \mathrm{C}$; McNeil et $a .^{25}$ reported that a carbon-coated $\mathrm{LiFePO}_{4}(0.5-1.0 \mu \mathrm{m})$ exhibited a specific capacity of $129 \mathrm{mAhg}^{-1}$ at $1 \mathrm{C}$; Wang et al. reported that $0.5 \mu \mathrm{m} \mathrm{LiFePO}_{4}$ could exhibit an initial capacity of $151 \mathrm{mAhg}^{-1}$ at $1 \mathrm{C}$ and $58 \mathrm{mAhg}^{-1}$ at $10 \mathrm{C}$, but with limited cyclability ${ }^{26,27}$; larger $(>5 \mu \mathrm{m}) \mathrm{LiFePO}_{4}$ particles have been identified to have very poor performance even when coated with conducting carbon ${ }^{25,26}$. So far, no facile procedure has been reported to make high-performance micron-sized $\mathrm{LiFePO}_{4}$, possibly due to the limited robustness of the coatings that cannot keep the integrity of the $\mathrm{LiFePO}_{4}$ particles during discharge and charging, particularly at high rates ${ }^{27}$.

Here we report a room-temperature method that can spontaneously coat micron-sized $(\sim 1.01 \mu \mathrm{m}) \mathrm{LiFePO}_{4}$ uniformly with a thin conducting polymer of polyphenylene, as depicted in Fig. 1. The coated $\mathrm{LiFePO}_{4}$, compared with its pristine counterpart, has demonstrated enhanced electrical conductivity, high rate capability and excellent cyclability when used as a 'carbon additive free' cathode material for rechargeable Li-ion batteries. In addition, the bonding of polyphenylene to $\mathrm{LiFePO}_{4}, \mathrm{Li}_{1-}$ ${ }_{x} \mathrm{FePO}_{4}$ and $\mathrm{FePO}_{4}$ has been explored by performing density functional theory (DFT) calculations for the adsorption of the phenyl radical on model surfaces of these compounds. It is concluded that phenyl preferentially forms a strong chemical bond to surface $\mathrm{O}$ sites under typical experimental and battery operational conditions, which could be disrupted in the unlikely event that the surface of $\mathrm{LiFePO}_{4}$ becomes completely lithiated.

\section{Results}

Reaction of $\mathrm{LiFePO}_{4}$ and $\mathrm{C}_{6} \mathbf{H}_{5} \mathbf{N}_{2}^{+} \mathbf{B F}_{4}^{-}$. It is known that when an aromatic diazonium salt $\left(\mathrm{ArN}_{2}^{+} \mathrm{X}^{-}\right)$is subjected to electrochemical or chemical reduction or thermal decomposition, an aryl radical $\left(\mathrm{Ar}^{*}\right)$ will form, which is reactive and is an effective agent for surface functionalization of many kinds of substrates ${ }^{28}$. The obtained organic layers strongly adhere to the substrates because a covalent bond is thought to form between the substrate surface and the aryl radicals ${ }^{29-32}$. Although most of the organic layers reported in the literatures are insulating ${ }^{28}$, a few of them are indeed conducting when certain diazonium precursors are used $^{31,33,34}$. One such diazonium salt is benzenediazonium tetrafluoroborate $\left(\mathrm{C}_{6} \mathrm{H}_{5} \mathrm{~N}_{2}^{+} \mathrm{BF}_{4}^{-}\right)$, which can be easily and economically prepared in a single-step synthesis ${ }^{31}$ (Supplementary Figs 1 and 2 for the nuclear magnetic resonance (NMR) and electrospray ionization mass spectrometry (ESI-MS) characterization) and is employed here as the radical-generating agent to functionalize the micron-sized pristine $\mathrm{LiFePO}_{4}$. Powder $\mathrm{X}$-ray diffraction (PXRD), scanning electron microscopy (SEM)/ transmission electron microscopy (TEM) and Fourier transform infrared (FTIR) characterizations (Supplementary Figs 3-5) showed that the micron-sized $\mathrm{LiFePO}_{4}$ is of pure phase and contains no adventitious impurities such as $\mathrm{Li}_{2} \mathrm{CO}_{3}$ and $\mathrm{LiOH}$.

To demonstrate the feasibility of the spontaneous reaction of $\mathrm{LiFePO}_{4}$ and $\mathrm{C}_{6} \mathrm{H}_{5} \mathrm{~N}_{2}^{+} \mathrm{BF}_{4}^{-}$, an electrochemical measurement was performed. In a three-compartment cell, $\mathrm{C}_{6} \mathrm{H}_{5} \mathrm{~N}_{2}^{+} \mathrm{BF}_{4}^{-}$is electrochemically reduced at an $\mathrm{Au}$ electrode, where partially delithiated $\mathrm{LiFePO}_{4}$ (that is, $\mathrm{Li}_{1}{ }_{x} \mathrm{FePO}_{4}, x=0.1$ ) is used as the

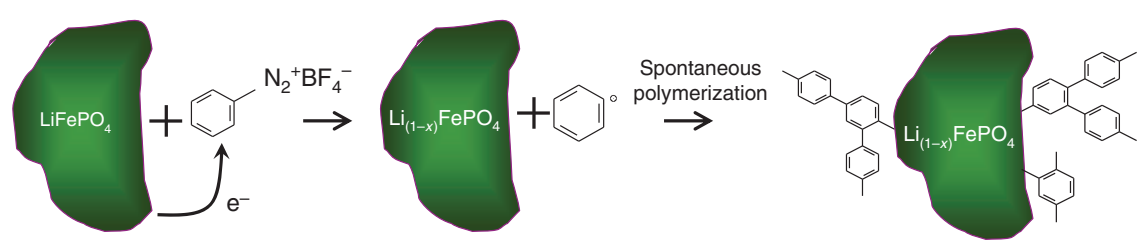

Figure 1 | Schematic illustration of the reaction of LiFe $\mathbf{P O}_{\mathbf{4}}$ and $\mathbf{C}_{\mathbf{6}} \mathbf{H}_{\mathbf{5}} \mathbf{N}_{\mathbf{2}}^{+} \mathbf{B F}_{\mathbf{4}}^{-}$. The diazonium cations are reduced to phenyl radicals by electrons from $\mathrm{LiFePO}_{4}$ particles, while at the same time $\mathrm{LiFePO}_{4}$ is oxidized to its partially delithiated state of $\mathrm{Li}_{1}{ }_{x} \mathrm{FePO}_{4}$. The reactive phenyl radicals bond to the surface of $\mathrm{Li}_{1-x} \mathrm{FePO}_{4}$ forming conducting polyphenylene coatings. 


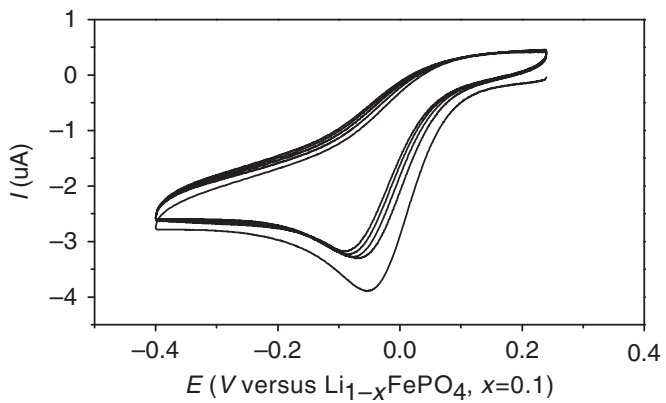

Figure 2 | Measurement of the reduction potential of $\mathrm{C}_{6} \mathrm{H}_{5} \mathrm{~N}_{2}^{+} \mathrm{BF}_{4}^{-}$. Electroreduction of $1 \mathrm{mM} \mathrm{C}_{6} \mathrm{H}_{5} \mathrm{~N}_{2}^{+} \mathrm{BF}_{4}^{-}$at a 2-mm diameter Au electrode in a three-compartment cell thermostated at $21^{\circ} \mathrm{C}$. Supporting electrolyte is $0.1 \mathrm{M} \mathrm{TBAClO}_{4}$-acetonitrile and scan rate is $0.1 \mathrm{Vs}^{-1}$.

reference electrode because of its highly stable potential of $3.43 \mathrm{~V}$ versus $\mathrm{Li}^{+} / \mathrm{Li}^{35}$. Figure 2 shows the cyclic voltammograms for the first 1-5 cycles. One distinct feature of the $I-E$ curves is that the successive peak currents corresponding to the electroreduction of $\mathrm{C}_{6} \mathrm{H}_{5} \mathrm{~N}_{2}^{+}$to $\mathrm{C}_{6} \mathrm{H}_{5}{ }^{-}$radical does not decrease drastically, which is different from the insulating film-forming diazonium salts, such as 4-nitrobenzenediazonium tetrafluoroborate ${ }^{36}$, a benchmark compound for electrografting of diazonium salt. This observation is consistent with the conducting nature of the grafted polyphenyl layers on the electrode ${ }^{31}$. Although the reduction peak potential is located at $-0.05 \mathrm{~V}$, the onset potential of the electroreduction of $\mathrm{C}_{6} \mathrm{H}_{5} \mathrm{~N}_{2}^{+} \mathrm{BF}_{4}^{-}$is around $0.1 \mathrm{~V}$, which is positive to the $\mathrm{Li}_{1-x} \mathrm{FePO}_{4}$ reference. It should be noted that the open circuit potential of the pristine $\mathrm{LiFePO}_{4}$ electrode against $\mathrm{Li}^{+} / \mathrm{Li}$ is in the range of $2.5-3.0 \mathrm{~V}$, thus providing an even greater driving force for the reduction of $\mathrm{C}_{6} \mathrm{H}_{5} \mathrm{~N}_{2}^{+} \mathrm{BF}_{4}^{-}$. Recently, Madec et al. ${ }^{37}$ have used nitrobenzenediazonium salts to functionalize pristine $\mathrm{LiFePO}_{4}$ and limited reaction extent has been observed, which could be due to the insulating nature of the polymers formed from the nitrobenzenediazonium precursors.

Following the realization that $\mathrm{LiFePO}_{4}$ can reduce $\mathrm{C}_{6} \mathrm{H}_{5} \mathrm{~N}_{2}^{+}$ $\mathrm{BF}_{4}^{-}$to the $\mathrm{C}_{6} \mathrm{H}_{5}$ radical, three reactions were conducted with molar ratios of $\mathrm{LiFePO}_{4}: \mathrm{C}_{6} \mathrm{H}_{5} \mathrm{~N}_{2}^{+} \mathrm{BF}_{4}^{-}$of 1:5, 1:1 and 1:0.05, respectively. The obtained products were subjected to structural and compositional analysis with the aim of understanding the extent and kinetics of the reaction. PXRD analysis (Fig. 3a) of the products after $12 \mathrm{~h}$ of reaction shows that the reaction, as expected, produces a new phase, that is, $\mathrm{FePO}_{4}$, and that the amount of the $\mathrm{FePO}_{4}$ increases with that of the added $\mathrm{C}_{6} \mathrm{H}_{5} \mathrm{~N}_{2}^{+}$ $\mathrm{BF}_{4}^{-}$. However, the excess $\mathrm{C}_{6} \mathrm{H}_{5} \mathrm{~N}_{2}^{+} \quad \mathrm{BF}_{4}^{-}$cannot completely transform $\mathrm{LiFePO}_{4}$ to $\mathrm{FePO}_{4}$, which means the reaction could be a self-limiting process. At molar ratios of $\mathrm{LiFePO}_{4}: \mathrm{C}_{6} \mathrm{H}_{5} \mathrm{~N}_{2}^{+} \mathrm{BF}_{4}^{-}$ of $1: 5$ and $1: 1$, around 48 and $44 \%$ of the pristine $\mathrm{LiFePO}_{4}$ were oxidized to $\mathrm{FePO}_{4}$, respectively, as determined by a Rietveld refinement procedure ${ }^{38}$ (Supplementary Fig. 6 and Table 1 for details). These two products contain a high ratio of $\mathrm{FePO}_{4}$, which is not beneficial to the direct application as cathode material of Li-ion battery because of the severe $\mathrm{Li}^{+}$ion loss. However, the reaction of $\mathrm{LiFePO}_{4}$ and $\mathrm{C}_{6} \mathrm{H}_{5} \mathrm{~N}_{2}^{+} \mathrm{BF}_{4}^{-}$with molar ratio of 1:0.05 shows a very small amount of $\mathrm{FePO}_{4}$ is formed (4.3\% as measured indirectly by element analysis and online mass spectrometry, instead of Rietveld refinement due to the very weak PXRD signal of $\mathrm{FePO}_{4}$ phase, see Supplementary Fig. 6 and Table 1 for the fitting results) and thus much less $\mathrm{Li}$ is extracted, as seen in Fig. 3a (blue curve). It is this reaction with less $\mathrm{C}_{6} \mathrm{H}_{5} \mathrm{~N}_{2}^{+} \mathrm{BF}_{4}^{-}$ that we will focus on.

First we conducted a quantitative online mass spectrometric investigation (the technical details may be found in refs 39,40) of
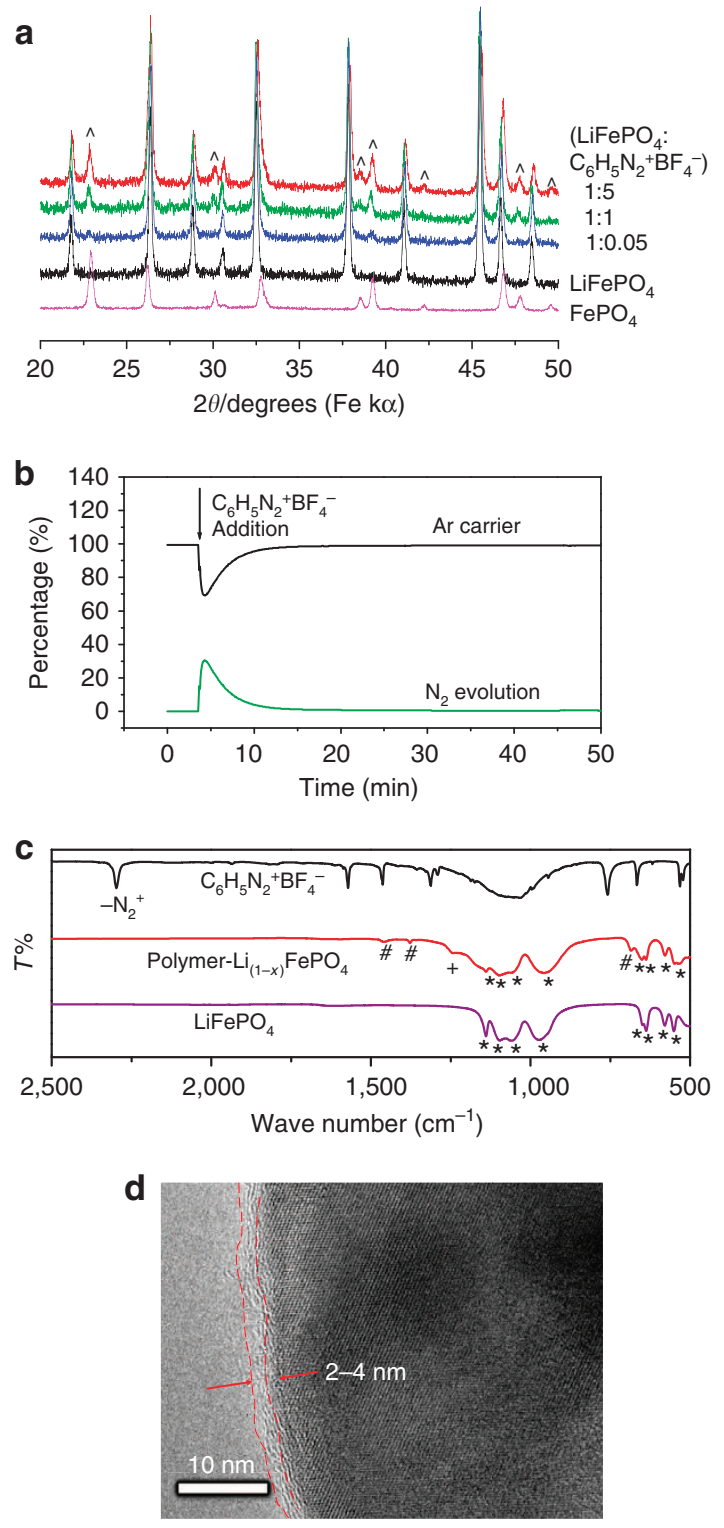

Figure 3 | Characterizations of the reaction of LiFePO ${ }_{4}$ and $\mathrm{C}_{6} \mathrm{H}_{5} \mathbf{N}_{\mathbf{2}}^{+} \mathrm{BF}_{4}^{-}$. (a) PXRD patterns of the reaction products of $\mathrm{LiFePO}_{4}$ and $\mathrm{C}_{6} \mathrm{H}_{5} \mathrm{~N}_{2}^{+} \mathrm{BF}_{4}^{-}$ at different molar ratios (1:5, 1:1 and 1:0.05), together with pure phase $\mathrm{LiFePO}_{4}$ and $\mathrm{FePO}_{4}$. The symbol ' highlights the evolution of $\mathrm{FePO}_{4}$ phase. (b) Quantitative online mass spectrometric analysis of $\mathrm{N}_{2}$ gas evolution of the reaction of $0.162 \mathrm{~g} \mathrm{LiFePO}$ and $10 \mathrm{mg} \mathrm{C}_{6} \mathrm{H}_{5} \mathrm{~N}_{2}^{+} \mathrm{BF}_{4}^{-}$. (c) FTIR of the reaction products of $\mathrm{LiFePO}_{4}$ and $\mathrm{C}_{6} \mathrm{H}_{5} \mathrm{~N}_{2}^{+} \mathrm{BF}_{4}^{-}$with molar ratio of 1:0.05, together with the spectra of $\mathrm{LiFePO}_{4}$ and $\mathrm{C}_{6} \mathrm{H}_{5} \mathrm{~N}_{2}^{+} \mathrm{BF}_{4}^{-}$. The symbols ${ }^{*},+$ and \# denote bands associated with $\mathrm{LiFePO}_{4}, \mathrm{FePO}_{4}$ and polyphenylene, respectively. (d) TEM of polyphenylene-coated $\mathrm{LiFePO}_{4}$

the reaction of $\mathrm{LiFePO}_{4}$ and $\mathrm{C}_{6} \mathrm{H}_{5} \mathrm{~N}_{2}^{+} \mathrm{BF}_{4}^{-}$. In a typical experiment, $0.162 \mathrm{~g}$ of $\mathrm{LiFePO}_{4}$ was dispersed in acetonitrile in a reaction vial that was incorporated into the purging system of an online mass spectrometer. Before mixing with $\mathrm{C}_{6} \mathrm{H}_{5} \mathrm{~N}_{2}^{+} \mathrm{BF}_{4}^{-}$, only the signal of the Ar carrier gas was observed. On addition of $\mathrm{C}_{6} \mathrm{H}_{5} \mathrm{~N}_{2}^{+} \mathrm{BF}_{4}^{-}$solution (containing $10 \mathrm{mg}$ of the diazonium salt as indicated by the arrow in Fig. 3b), the signal of $\mathrm{N}_{2}$ increased abruptly and the reaction finished within $20 \mathrm{~min}$. The evolved $\mathrm{N}_{2}$ gas was quantified, according to a procedure published previously ${ }^{39,40}$, to be $1.03 \mathrm{ml}(0.046 \mathrm{mmol})$, while the expected $\mathrm{N}_{2}$ volume was $1.15 \mathrm{ml}(0.051 \mathrm{mmol})$. This discrepancy may be due 
to minor side reactions that do not release $\mathrm{N}_{2}$ gas ${ }^{41}$. To verify the formation of the conducting polyphenyl polymers on $\mathrm{LiFePO}_{4}$, the solid product was analysed with FTIR. Figure $3 \mathrm{c}$ shows the FTIR spectra of the $\mathrm{LiFePO}_{4}$ after reaction, and also the pristine $\mathrm{LiFePO}_{4}$ (associated bands are marked with ${ }^{\star}$ ) and $\mathrm{C}_{6} \mathrm{H}_{5} \mathrm{~N}_{2}^{+} \mathrm{BF}_{4}^{-}$ for comparison purposes. The band in the $2,300-2,130 \mathrm{~cm}^{-1}$ region corresponding to the stretching of the $\mathrm{N} \equiv \mathrm{N}^{+}$bond of the $\mathrm{C}_{6} \mathrm{H}_{5} \mathrm{~N}_{2}^{+} \mathrm{BF}_{4}^{-}$is not present in the solid product after reaction, which confirms the loss of $\mathrm{N}_{2}$ during the reaction, consistent with the online mass spectrometric results. In addition, a new band at $1,240 \mathrm{~cm}^{-1}$ (marked with + in Fig. 3c, red curve) found in the spectrum of the solid product after reaction indicates the formation of $\mathrm{FePO}_{4}$ (refs 42,43). The bands at 1,456 and $1,375 \mathrm{~cm}^{-1}$, corresponding to the stretching of $\mathrm{C}=\mathrm{C}$ bonds in aromatic rings, together with a stronger band at $686 \mathrm{~cm}^{-1}$ (marked with \# in Fig. 3c, red curve) associated with different types of aromatic substitutions ${ }^{44}$, indicate the formation of polyphenyl polymers. The different types of substitutions reflect the non-regiospecific attack of aryl radicals at those sites where the molecules are already attached to the surface, which has been found previously in the multilayers from diazonium reactions ${ }^{31,36}$.

Figure $3 \mathrm{~d}$ shows the TEM micrograph of the polyphenylenecoated $\mathrm{LiFePO}_{4}$, in which a coating with a thickness of $2-4 \mathrm{~nm}$ has been observed for isolated particles. The formation of the polymer coating has also been proved by a high-angle annular scanning transmission electron microscopy equipped with a energy-dispersive X-ray detector for the elemental mapping of a single $\mathrm{LiFePO}_{4}$ particle after reaction (Supplementary Fig. 7). Although the PXRD data (Fig. 3a, blue curve) of the $\mathrm{LiFePO}_{4}$ after reaction with diazonium salt show a very weak signal of $\mathrm{FePO}_{4}$, the co-existence of two phases of $\mathrm{LiFePO}_{4}$ and $\mathrm{FePO}_{4}$ within a single particle (Supplementary Fig. 8) has been observed by annular bright-field scanning TEM ${ }^{45}$. We also noticed that the extended exposure of the polymer under electron beam causes degradation. Similar phenomena have been observed previously for polyaniline-coated noble metal particles ${ }^{46}$. The weight percentage of polyphenylene in the composite was determined by elemental analysis to be $2.0 \%$ (wt\%), which is consistent with the value measured by online mass spectrometry $2.1 \%$ (wt\%). The latter is transformed from a $4.3 \%$ (mol\%) of $\mathrm{LiFePO}_{4}$ that is oxidized to $\mathrm{FePO}_{4}$, by taking into account that the reaction occurs according to $\mathrm{LiFePO}_{4}+\mathrm{PhN}_{2}^{+} \rightarrow \mathrm{FePO}_{4}+\mathrm{Ph} \bullet+\mathrm{Li}^{+}+\mathrm{N}_{2}$ and that the generated $\mathrm{Ph} \bullet$ forms polymers on $\mathrm{LiFePO}_{4}$ surfaces. The formation of conducting polymer was further evidenced by the conductivity measurement of pressed powders, in which the polyphenylene-coated samples showed an electronic conductivity of $0.03 \mathrm{~S} \mathrm{~cm}^{-1}$, while pristine $\mathrm{LiFePO}_{4}$ is less than $10^{-6} \mathrm{~S} \mathrm{~cm}^{-1}$ (refs 7,8 ). Higher conductivity of polyphenylene has previously been reported by Shacklette et al. ${ }^{47}$, who demonstrated that the conductivity of polyphenylene can be increased to $50 \mathrm{~S} \mathrm{~cm}^{-1}$ by doping with $\mathrm{K}^{+}$, and even to $500 \mathrm{~S} \mathrm{~cm}^{-1}$ by doping with $\mathrm{AsF}_{5}^{-}$.

Electrochemical performance. The obtained polymer/ $/ \mathrm{LiFePO}$ composite had a tap density of $2.02 \mathrm{~g} \mathrm{~cm}^{-3}$ that was higher than the values reported for nano-sized $\mathrm{LiFePO}_{4}$ (typically in the range of $1.0-1.5 \mathrm{~g} \mathrm{~cm}^{-3}$ ), and were mixed with polyvinylidene difluoride (PVDF) binder (9:1 wt/wt) and casted on an $\mathrm{Al}$ foil current collector to make a cathode (mass loading in the range of $2-3 \mathrm{mg} \mathrm{cm}^{-2}$ ) for Li-ion cells. It is worth noting that the cathode does not contain any conducting carbon such as Super P, an additive that is extensively used in the practical cathode fabrication to ensure electronic conductivity throughout the electrode. When tested at a lower rate of $0.1 \mathrm{C}$, a capacity of $165 \mathrm{mAh} \mathrm{g}^{-1}$ (the capacity is normalized to the expected mass of the active material of the cathode after complete lithiation) was achieved, as seen in Fig. 4a,b. This value is close to the theoretical capacity of $\mathrm{LiFePO}_{4}\left(170 \mathrm{mAhg}^{-1}\right)$, while very limited capacity is obtained for $\mathrm{LiFePO}_{4}$ treated in the absence of $\mathrm{C}_{6} \mathrm{H}_{5} \mathrm{~N}_{2}^{+} \mathrm{BF}_{4}^{-}$ (Supplementary Fig. 9). When the carbon additive of Super P was used, improved electrochemical performance, relative to that of pristine $\mathrm{LiFePO}_{4}$, has been obtained (Supplementary Fig. 10), which was, however, still inferior to the performance of the polyphenylene coating, particularly at higher rates. Electrochemical impedance spectroscopy has been used to probe the interfacial reaction kinetics, and smaller interfacial reaction resistance has been identified for polyphenylene-coated $\mathrm{LiFePO}_{4}$ (Supplementary Fig. 11), which could account for the improved performance at higher rates. The $\mathrm{Li}^{+}$diffusion within the micron-sized $\mathrm{LiFePO}_{4}$ has also been measured with the electrochemical impedance spectroscopy, and diffusion coefficients in the range of $10^{-16}-10^{-14} \mathrm{~cm}^{2} \mathrm{~s}^{-1}$ comparable to that of nano$\mathrm{LiFePO}_{4}$ have been obtained ${ }^{48}$ (Supplementary Fig. 11 and Table 2). The performance of polyphenylene-coated $\mathrm{LiFePO}_{4}$ is significant since the prepared cathode contains no conducting carbon additive, and it shall be emphasized here that conducting carbon additive is not electrochemically active and therefore
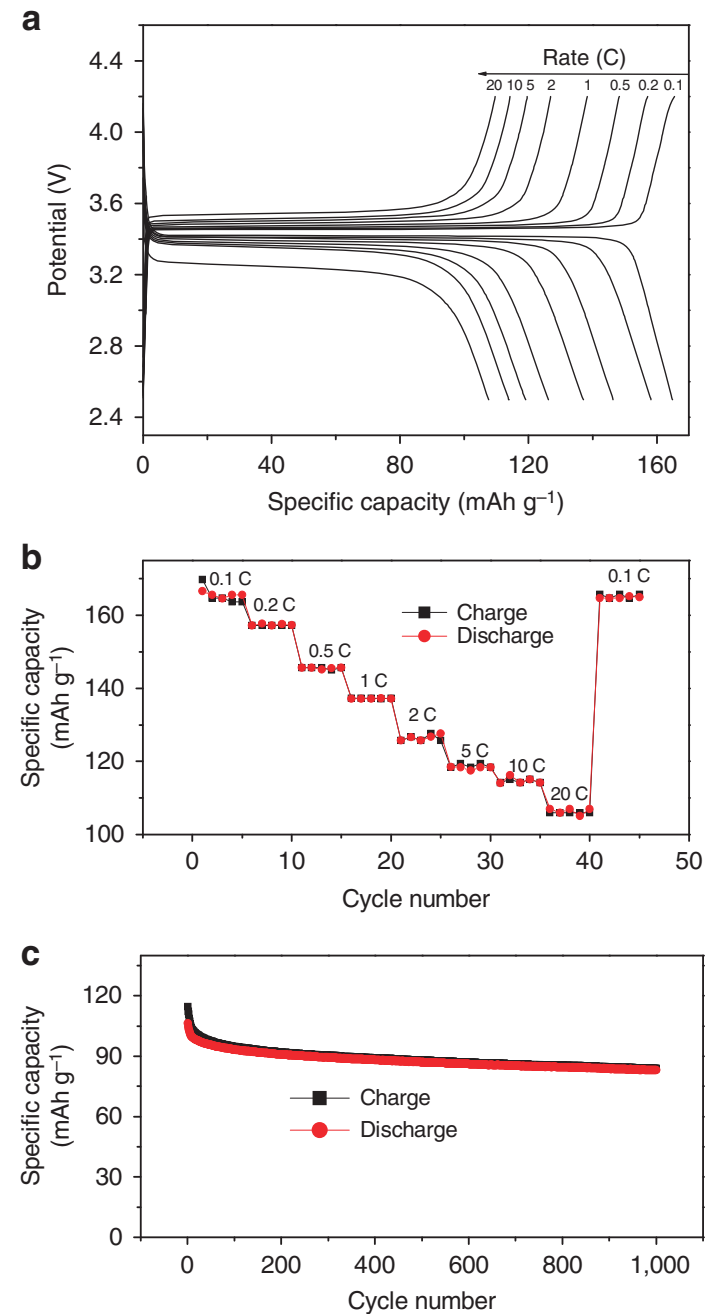

Figure 4 | Electrochemical performance of polyphenylene-LiFePO composites. (a) Charge/discharge curves of polyphenylene-LiFePO ${ }_{4} / \mathrm{PVDF}$ (9:1 wt/wt) at various rates from 0.1 to 20 C; (b) charge/discharge capacity versus cycle number; (c) high rate performance at $20 \mathrm{C}$. 
diminishes the practical energy density of the electrode ${ }^{13}$. The ability to replace carbon with a conducting polyphenylene coating is for these reasons highly advantageous. Cycling at a higher rate of $20 \mathrm{C}$ for 1,000 cycles confirms the stability of the coating in the lithium-ion battery environment (Fig. 4c). Performances of the polyphenylene-coated $\mathrm{LiFePO}_{4}$ at different temperatures have also been tested, and the results at $0{ }^{\circ} \mathrm{C}$ demonstrated comparable performance at rates $<8 \mathrm{C}$ and somewhat degraded performance at rates $>12 \mathrm{C}$ (Supplementary Fig. 12). The high rate capability of the micron-sized $\mathrm{LiFePO}_{4}$ can be attributed to the formation of a metastable phase that can effectively decrease the energy battier of the nucleation and growth of a new phase, even the intrinsic $\mathrm{Li}^{+}$bulk diffusion coefficient of $\mathrm{LiFePO}_{4}$ is small ${ }^{49,50}$.

The interaction between $\mathrm{LiFePO}_{4} / \mathrm{FePO}_{4}$ and phenyl radicals. To address the issue of how polyphenylene is bonded to $\mathrm{LiFePO}_{4}$, we have performed DFT calculations using the phenyl radical as the probe molecule. As noted above, the initial reaction between $\mathrm{LiFePO}_{4}$ and $\mathrm{C}_{6} \mathrm{H}_{5} \mathrm{~N}_{2}^{+} \mathrm{BF}_{4}^{-}$can partially delithiates the former leading to the formation of lithium vacancies predominantly present on the surface region ${ }^{51}$. Furthermore, as previous studies have shown, typical discharge processes do not entirely convert $\mathrm{FePO}_{4}$ into $\mathrm{LiFePO}_{4}$ (ref. 52). Thus, we conclude that the surface region of $\mathrm{LiFePO}_{4}$ under typical experimental and operational conditions is best described either as $\mathrm{FePO}_{4}$ or as $\mathrm{LiFePO}_{4}$ with $\mathrm{Li}$ vacancies. The stoichiometric, fully lithiated $\mathrm{LiFePO}_{4}$ is included below for comparison purposes. The (010) termination is chosen because it is the dominant facet based on Wulff constructions for both $\mathrm{LiFePO}_{4}$ and $\mathrm{FePO}_{4}$ (ref. 53).

On $\mathrm{FePO}_{4}(010)$, phenyl is most stable on the $\mathrm{O}_{1}$ site (Fig. 5a) with a $\mathrm{C}-\mathrm{O}$ bond length $\left(d_{\mathrm{C}-\mathrm{O}}\right)$ of $1.420 \AA$, which is consistent
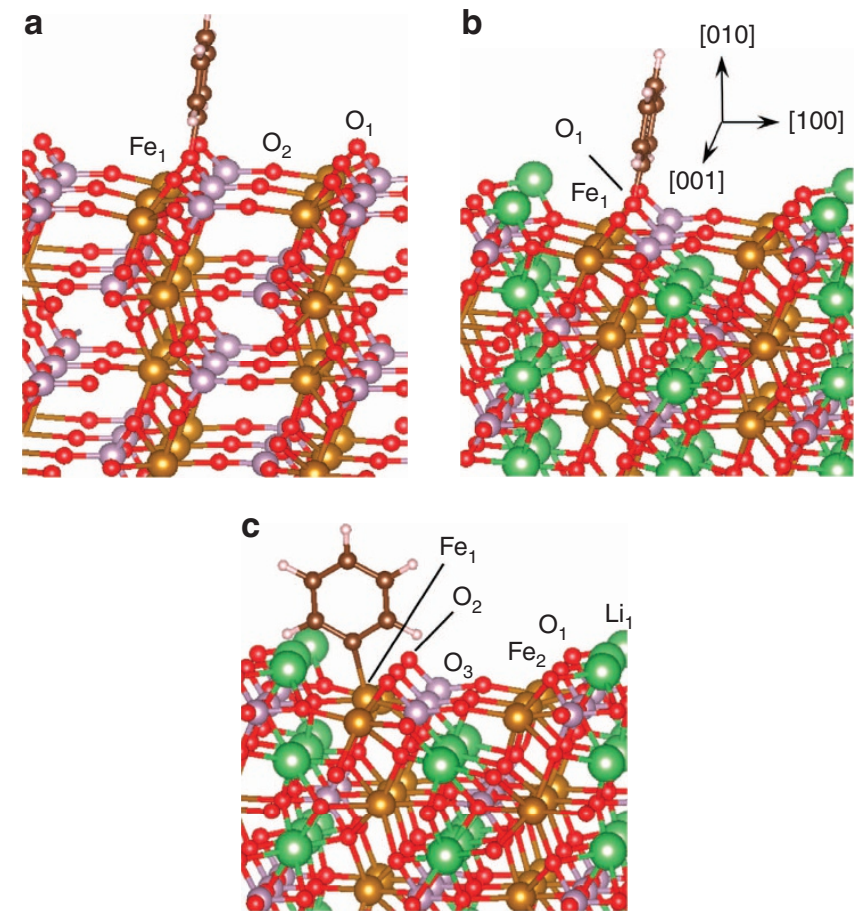

Figure 5 | DFT-calculated configurations of phenyl radical on $\mathbf{L i}_{\mathbf{1}}{ }_{-\mathbf{x}} \mathbf{F e P O} \mathbf{P}_{\mathbf{4}} \mathbf{( 0 1 0 )}$. Minimum energy adsorption configurations for a phenyl radical on (a) $\mathrm{FePO}_{4}(010)$, (b) $\mathrm{LiFePO}_{4}(010)$ with a surface $\mathrm{Li}$ vacancy and (c) stoichiometric $\mathrm{LiFePO}_{4}(010)$. The white, green, black, red, purple and gold spheres represent $\mathrm{H}, \mathrm{Li}, \mathrm{C}, \mathrm{O}, \mathrm{P}$ and Fe atoms, respectively. The orientation of all of the surface models is the same and is indicated in $\mathbf{b}$. with covalent $\mathrm{C}-\mathrm{O}$ single bonds. The adsorption energy $\left(\Delta E_{\mathrm{ads}}\right)$ is $-2.80 \mathrm{eV}$, indicating the bond to be chemical in nature. We have not located any previous report of the phenyl adsorption energy on metal oxides for comparison. DFT-calculated $\Delta E_{\text {ads }}$ of phenyl on transition metal surfaces range widely from -1.04 (on $\mathrm{Au}(111)$ ) to -2.81 (on $\mathrm{Ti}(0001)) \mathrm{eV}^{54}$. Van der Waals forces may further stabilize phenyl adsorption ${ }^{55}$, but are not expected to change the site preference of phenyl on these surfaces. Phenyl adsorption on $\mathrm{LiFePO}_{4}(010)$ with a $\mathrm{Li}$ vacancy is weaker than on $\mathrm{FePO}_{4}(010)$, although phenyl still preferentially binds to an $\mathrm{O}$ site (Fig. 5b) with a considerably exothermic $\Delta E_{\mathrm{ads}}$ of $-1.55 \mathrm{eV}$ and $d_{\mathrm{C}-\mathrm{O}}=1.414 \AA$. For comparison, phenyl adsorption on stoichiometric $\mathrm{LiFePO}_{4}(010)$ has a $\Delta E_{\text {ads }}$ of only $-0.18 \mathrm{eV}$ (most stable $\mathrm{O}$ site is $\mathrm{O}_{2}$, Fig. $5 \mathrm{c}$ ) with $d_{\mathrm{C}-\mathrm{O}}=1.410 \AA$.

In contrast, the adsorption of phenyl on Fe sites varies much less across the three model surfaces. Phenyl on the best Fe site $\left(\mathrm{Fe}_{1}\right.$, Fig. 5a) has $d_{\mathrm{C}-\mathrm{Fe}}=2.239 \AA$ and $\Delta E_{\mathrm{ads}}=-0.59 \mathrm{eV}$ on $\mathrm{FePO}_{4}(010) ; 2.113 \AA$ and $-0.84 \mathrm{eV}$ on $\mathrm{LiFePO}_{4}(010)$ with a $\mathrm{Li}$ vacancy $\left(\mathrm{Fe}_{1}\right.$, Fig. 5b), and $2.136 \AA$ and $-0.94 \mathrm{eV}$, respectively, on stoichiometric $\mathrm{LiFePO}_{4}(010)\left(\mathrm{Fe}_{1}\right.$, Fig. $\left.5 \mathrm{c}\right)$.

Our DFT results suggest that the phenyl radical (and thus the polyphenylene coating) is most likely attached to the $\mathrm{LiFePO}_{4}$ surface via $\mathrm{O}$ sites. Although the strength of the phenyl-O bond varies with the extent of surface lithiation, a strong chemical bond is expected under typical experimental and operational conditions as the surface is expected to be always deficient in $\mathrm{Li}$ to some extent. However, if the surface were to be completely lithiated, that is, by over-discharging a battery, the bonding of the coating to the surface could be disrupted because the bond strength would be weakened considerably and the preferred bonding site would shift from $\mathrm{O}$ to $\mathrm{Fe}$.

\section{Discussion}

It has long been desirable to obtain high-performance $\mathrm{LiFePO}_{4}$ particles with sizes approaching micrometres ${ }^{24-27}$. In this way, a high volumetric energy density of the Li-ion batteries resulted from a high tap density of micron-sized $\mathrm{LiFePO}_{4}$ particles can be achieved, which is critically important for electric vehicle applications ${ }^{1}$. Practically, it has been difficult to coat large $\mathrm{LiFePO}_{4}$ particles with uniform carbon coatings by calcination of carbon sources (usually organic small or macro molecules) and the preformed $\mathrm{LiFePO}_{4}$ particles, possibly because of the inhomogeneous mixing of carbon sources and the large $\mathrm{LiFePO}_{4}$ particles, which frequently results in phase-separated mixture of carbon and $\mathrm{LiFePO}_{4}$. On the other hand, simultaneous calcination of carbon sources and $\mathrm{LiFePO}_{4}$ precursors often produces only nano-sized carbon-coated $\mathrm{LiFePO}_{4}$ particles, because the formation of carbon phase inhibits the further growth of the $\mathrm{LiFePO}_{4}$ phase, which has been proved in numerous literatures on the synthesis of nano- $\mathrm{LiFePO}_{4}$ (refs 3,4). Furthermore, as pointed out by Zhou and co-workers ${ }^{16}$, carbon coatings on $\mathrm{LiFePO}_{4}$ produced by heat treatment tend to be irregular and not well connected to the particles, particularly for large $\mathrm{LiFePO}_{4}$ particles, and hence do not fully deliver the expected performance for battery applications. Actually, the difficulty encountered when coating large $\mathrm{LiFePO}_{4}$ particles with a uniform carbon coating by calcination has motivated us to find alternatives to coat large $\mathrm{LiFePO}_{4}$ particles with other conducting materials in the first place, as exemplified in this work.

To demonstrate the importance of the conductive coatings (either carbon or polymer coatings) on large $\mathrm{LiFePO}_{4}$, we have tested the electrochemical performance (Supplementary Fig. 9) of bare $\mathrm{LiFePO}_{4}$ by preparing cathode of binder $+\mathrm{LiFePO}_{4}(1: 9 \mathrm{wt} / \mathrm{wt})$. 
To compare the performances between polyphenylene- and carbon-coated $\mathrm{LiFePO}_{4}$, we prepared and tested the cathode of binder + polyphenylene-coated $\mathrm{LiFePO}_{4} \quad(1: 9 \mathrm{wt} / \mathrm{wt})$, and the cathode of binder + carbon additive $+\mathrm{LiFePO}_{4} \quad(1: 1: 8 \mathrm{wt} / \mathrm{wt})$ (Fig. 4; Supplementary Fig. 10). These results highlight the importance of the high-quality conducting coatings on the electrochemical performance of large pristine $\mathrm{LiFePO}_{4}$ particles, and that for improving the performance of micron-sized $\mathrm{LiFePO}_{4}$ particles, polyphenylene clearly outperforms the typical conducting carbon.

On the basis of the electrochemical measurement results of pristine, carbon-coated and polymer-coated $\mathrm{LiFePO}_{4}$ (Fig. 4; Supplementary Figs 9 and 10), and particularly on the fact that large $\mathrm{LiFePO}_{4}$ usually could not be easily coated with high-quality carbon coatings and therefore could only exhibit limited performance even in the presence of conducting carbon ${ }^{24-27}$, we attributed the improved electrochemical performance of polymer-coated large $\mathrm{LiFePO}_{4}$ particles to the intimate bonding between $\mathrm{LiFePO}_{4}$ and polyphenylene, a result of the surfaceinitialized electrografting of a diazonium salt, which is also supported by our DFT calculations. Another factor that might attribute to the improved performance of polymer-coated $\mathrm{LiFePO}_{4}$ is that $\mathrm{Li}^{+}$diffusion coefficient in polyphenylene $\left(\sim 1.32 \times 10^{-8} \mathrm{~cm}^{2} \mathrm{~s}^{-1}\right)^{56}$ is higher than in amorphous carbon coatings $\left(\sim 9.0 \times 10^{-11} \mathrm{~m}^{2} \mathrm{~s}^{-1}\right)^{57}$. At higher rates, the $\mathrm{Li}^{+}$ diffusion within the coatings that separate the $\mathrm{LiFePO}_{4}$ particles and $\mathrm{Li}^{+}$containing electrolytes become crucially important, because better $\mathrm{Li}^{+}$ion conducting coatings can ensure a rapid exchange of $\mathrm{Li}^{+}$ions between the $\mathrm{LiFePO}_{4}$ phase and the liquid $\mathrm{Li}^{+}$electrolyte.

In summary, the energy capabilities of micron-sized $\mathrm{LiFePO}_{4}$ have been unlocked in this work. Using the intrinsic reducing power of $\mathrm{LiFePO}_{4}$ towards a diazonium salt of $\mathrm{C}_{6} \mathrm{H}_{5} \mathrm{~N}_{2}^{+} \mathrm{BF}_{4}^{-}$, a covalently bonded conducting polymer coating of polyphenylene can spontaneously form on pristine $\mathrm{LiFePO}_{4}$. The reaction mechanism has been studied in a detailed way by a range of complementary techniques coupled with theoretical calculations. More importantly, we have shown that the standard carbon coating generated by pyrolysis reaction can be substituted by the polymer coatings without emission of volatile organic compounds. Moreover, the polymer-coated $\mathrm{LiFePO}_{4}$ can be used directly as 'carbon additive free' electrodes with desired electrochemical performance for rechargeable Li-ion batteries. Combined, the method reported here represents a potential replacement of the industrial standard of carbon coating $\mathrm{LiFePO}_{4}$ with the spontaneous formation of conducting polymers from diazonium salt reactions.

\section{Methods}

Procedure. Carbon-free $\mathrm{LiFePO}_{4}$ powder was prepared according to a published procedure ${ }^{18}$. In brief, the stoichiometric amount of precursors of $\mathrm{FePO}_{4}\left(\mathrm{H}_{2} \mathrm{O}\right)_{2}$ and $\mathrm{Li}_{2} \mathrm{CO}_{3}$ were thoroughly mixed together in isopropanol. After drying, the blend was heated at $700{ }^{\circ} \mathrm{C}$ under reducing atmosphere. The obtained $\mathrm{LiFePO}_{4}$ particle has an average size of $1.01 \mu \mathrm{m}$ (Supplementary Table 3). $\mathrm{C}_{6} \mathrm{H}_{5} \mathrm{~N}_{2}^{+} \mathrm{BF}_{4}^{-}$ was synthesized as follows ${ }^{31}$. A total of $0.01 \mathrm{~mol}$ of newly distilled aniline was dissolved in $50 \mathrm{ml}$ solution of $0.1 \mathrm{M}$ of $\mathrm{HCl}$. After cooling the solution at $0{ }^{\circ} \mathrm{C}$ with ice, a concentrated solution of $\mathrm{NaNO}_{2}(0.015 \mathrm{~mol})$ in water was added for 20 -min reaction, then $0.012 \mathrm{~mol} \mathrm{NaBF}_{4}$ was added to precipitate the obtained diazonium cations. After filtration, the product was washed successively with cold water and ether. The powder was dried and kept in a freezer at $-18^{\circ} \mathrm{C}$. The reactions of $\mathrm{LiFePO}_{4}$ and $\mathrm{C}_{6} \mathrm{H}_{5} \mathrm{~N}_{2}^{+} \mathrm{BF}_{4}^{-}$with different molar ratios were conducted in acetonitrile. After reaction, the obtained products were subjected to a centrifugation also in acetonitrile. The supernatant after centrifuge was collected and examined by ultraviolet-visible to ensure the complete removal of the possible non-surface confined polymer and the starting material. The electrochemical properties of polyphenylene-LiFePO 4 were determined with CR2032-type coin cells using metallic lithium as the anode. The cathode was made by coating polyphenylene- $\mathrm{LiFePO}_{4}$ and a solution of PVDF (Kynar 2801; 90:10 wt/wt) in $\mathrm{N}$-methylpyrrolidone onto $\mathrm{Al}$ foil.
}

Characterization. Electroreduction of $\mathrm{C}_{6} \mathrm{H}_{5} \mathrm{~N}_{2}^{+} \mathrm{BF}_{4}^{-}$was conducted in an air-tight, three-compartment glass cell with valves to control the gas inlet and outlet. A polycrystalline Au disk electrode (diameter $2.0 \mathrm{~mm}$, CHI Inc.) was used as the working electrode and was polished with $0.05 \mu \mathrm{m}$ alumina slurry before use. A partially delithiated $\mathrm{Li}_{1-x} \mathrm{FePO}_{4}(x=0.1)$ coated on stainless steel mesh ( $\mathrm{LiFePO}_{4}$ :Super P:PVDF 80:10:10 wt/wt) was used as the reference electrode. All electrochemical measurements were carried out using a Biologic VMP3 electrochemical workstation. The conductivity of the coated material was measured in a D41 - 11C/ZM four-probe resistivity tester. The chemical structure of $\mathrm{C}_{6} \mathrm{H}_{5} \mathrm{~N}_{2}^{+} \mathrm{BF}_{4}^{-}$was checked by ${ }^{1} \mathrm{H}$ NMR (Avance III 400, Bruker) and ESIMS(Quattro Premier XE system, Waters). PXRD was carried out using a STOE STADI/P diffractometer operating in transmission mode with a primary beam monochromator and position-sensitive detector. Fe K $\alpha 1$ radiation $(\lambda=1.936 \AA)$ was employed. The details of online mass spectrometry were reported elsewhere ${ }^{39,40}$. The FTIR analysis was carried out with a Nicolet 6700 FTIR in transmission mode. Elemental analyses were performed using a Vario EL analyser. TEM images were recorded with JEOL JEM-2100F TEM operating at $200 \mathrm{kV}$. The experimental details for annular bright-field scanning TEM and high-angle annular scanning TEM for $\mathrm{LiFePO}_{4}$ were reported elsewhere ${ }^{45}$.

Theoretical calculations. Periodic DFT calculations were performed using the Perdew-Burke-Ernzerhof functional and the projected augmented wave method as implemented in the Vienna Ab initio Simulation Package (version 5.3) ${ }^{58}$. The Kohn-Sham valence states $(\mathrm{Fe}(3 d 4 s), \mathrm{Li}(2 s 2 p), \mathrm{O}(2 s 2 p), \mathrm{P}(3 s 3 p), \mathrm{C}(2 s 2 p)$ and $\mathrm{H}(1 s)$ ) were expanded in a plane wave basis up to a kinetic energy of $400 \mathrm{eV}$. As the electronic structures of both $\mathrm{LiFePO}_{4}$ and $\mathrm{FePO}_{4}$ are sensitive to electron correlation effects, the DFT $+\mathrm{U}$ approach was used ${ }^{59}$. The optimized U-values and lattice parameters for the bulk $\mathrm{LiFePO}_{4}$ and $\mathrm{FePO}_{4}$ were taken from Zhou et al. ${ }^{60}$ The electronic energies of $\mathrm{LiFePO}_{4}$ and $\mathrm{FePO}_{4}$ depend strongly on the magnetic state of the Fe atoms ${ }^{61}$. In accord with previous investigations, we found DFT $+\mathrm{U}$ to favour high-spin ferromagnetic and antiferromagnetic states over other spin orderings. As the binding energies of the phenyl radical on the $\mathrm{LiFePO}_{4}(010)$ and $\mathrm{FePO}_{4}(010)$ surfaces were observed to be reasonably insensitive to ferromagnetic/ antiferromagnetic ordering of the Fe ions, we report here results for high-spin ferromagnetic states, where the site projected atomic magnetic moments of $\mathrm{Fe}$ remain essentially identical to their computed bulk values ( 4.3 and $3.7 \mu_{\mathrm{B}}$ for $\mathrm{FePO}_{4}$ and $\mathrm{LiFePO}_{4}$, respectively). Following relaxation of the bulk atomic positions, symmetric (010) slabs were constructed according to the procedure outlined in ref. 51 . The dimensions of each slab correspond to $1 \mathbf{a} \times 2 \mathbf{b} \times 2 \mathbf{c}$ of the bulk lattice vectors (where $\mathbf{a}=10.42, \mathbf{b}=6.07$ and $\mathbf{c}=4.75 \AA$ for $\mathrm{LiFePO}_{4}$ and $\mathbf{a}=9.99$, $\mathbf{b}=5.88$ and $\mathbf{c}=4.87 \AA$ for $\mathrm{FePO}_{4}$ ), yielding 16 formula units per unit cell. Vacuum space $(13 \AA)$ was added along the $\mathbf{b}$ direction. The surface Brillouin zone was sampled with a $3 \times 1 \times 3 \mathrm{k}$-point mesh, which was confirmed to converge the total energies of both surfaces to within $3 \mathrm{meV}$ per formula unit. For $\mathrm{FePO}_{4}(010)$, the atomic positions of the top layer of $\mathrm{Fe}$ and $\mathrm{P}$ atoms along with all the $\mathrm{O}$ atoms coordinated to them (including subsurface $\mathrm{O}$ atoms) were relaxed, while holding the coordinates of the remaining atoms frozen in their bulk positions. For $\mathrm{LiFePO}_{4}(010)$, the same layer of $\mathrm{Fe}, \mathrm{P}$ and $\mathrm{O}$ atoms as in $\mathrm{FePO}_{4}(010)$ was relaxed, as well as the top two layers of $\mathrm{Li}$ atoms. The vacancy model was created by removing one of the two top-layer $\mathrm{Li}$ atoms in the surface unit cell that we used for $\mathrm{LiFePO}_{4}(010)$, with the surface relaxed again. The phenyl adsorbate was fully relaxed. All geometry relaxations were considered converged once the force in each relaxed degree of freedom fell below $0.03 \mathrm{eV}^{-1}$. The adsorption energy of phenyl was calculated as $\Delta E_{\text {ads }}=E_{\text {total }}-E_{\text {surface }}-E_{\text {phenyl }}$. Including the semi-core states of $\mathrm{Fe}$ and $\mathrm{Li}$ in the valence $(\mathrm{Fe}(3 \mathrm{~s} 3 \mathrm{p} 3 \mathrm{~d} 4 \mathrm{~s}), \operatorname{Li}(1 \mathrm{~s} 2 \mathrm{~s} 2 \mathrm{p}))$ and increasing the kinetic cutoff energy to $500 \mathrm{eV}$ were verified to changed adsorption energies by $<0.1 \mathrm{eV}$ on all three surfaces.

\section{References}

1. Armand, M. \& Tarascon, J. M. Building better batteries. Nature 451, 652-657 (2008).

2. Padhi, A. K., Nanjundaswamy, K. S. \& Goodenough, J. B. Phospho-olivines as positive-electrode materials for rechargeable lithium batteries. J. Electrochem. Soc. 144, 1188-1194 (1997).

3. Wang, J. \& Sun, X. Understanding and recent development of carbon coating on $\mathrm{LiFePO}_{4}$ cathode materials for lithium-ion batteries. Energy Environ. Sci. 5, 5163-5185 (2012).

4. Wang, Y., He, P. \& Zhou, H. Olivine $\mathrm{LiFePO}_{4}$ : development and future. Energy Environ. Sci. 4, 805-817 (2011).

5. Kang, B. \& Ceder, G. Battery materials for ultrafast charging and discharging. Nature 458, 190-193 (2009).

6. Zaghib, K., Goodenough, J. B., Mauger, A. \& Julien, C. Unsupported claims of ultrafast charging of $\mathrm{LiFePO}_{4} \mathrm{Li}$-ion batteries. J. Power Source 194, 1021-1023 (2009).

7. Chung, S. Y., Bloking, J. T. \& Chiang, Y. M. Electronically conductive phosphoolivines as lithium storage electrodes. Nat. Mater. 1, 123-128 (2002).

8. Nathalie, R., Abouimrane, A. \& Armand, M. From our readers: On the electronic conductivity of phospho-olivines as lithium storage electrodes. Nat Mater. 2, 702 (2003). 
9. Wagemaker, M., Ellis, B. L., Lützenkirchen-Hecht, D., Mulder, F. M. \& Nazar, L. F. Proof of supervalent doping in olivine $\mathrm{LiFePO}_{4}$. Chem. Mater. 20, 6313 (2008).

10. Hsu, K. F., Tsay, S. Y. \& Hwang, B. J. Synthesis and characterization of nano-sized $\mathrm{LiFePO}_{4}$ cathode materials prepared by a citric acid-based sol-gel route. J. Mater. Chem. 14, 2690-2695 (2004).

11. Gabrisch, H., Wilcox, J. D. \& Doeff, M. M. Carbon surface layers on a high-rate $\mathrm{LiFePO}_{4}$. Solid State Lett 9, A360-A363 (2006).

12. Delmas, C., Maccario, M., Croguennec, L., Le Cras, F. \& Weill, F. Lithium deintercalation in $\mathrm{LiFePO}_{4}$ nanoparticles via a domino-cascade model. Nat. Mater. 7, 665-671 (2008).

13. Chen, Z. \& Dahn, J. R. Reducing carbon in $\mathrm{LiFePO}_{4} / \mathrm{C}$ composite electrodes to maximize specific energy, volumetric energy, and tap density. J. Electrochem. Soc. 149, A1184-A1189 (2002).

14. Ravet, N. et al.in Proceedings of the 196th ECS meeting 127 (Honolulu, Hawaii, 1999).

15. Chen, H. et al. Pyrolysis characteristics of sucrose biomass in a tubular reactor and a thermogravimetric analysis. Fuel 95, 425-430 (2012).

16. Wang, Y., Wang, Y., Hosono, E., Wang, K. \& Zhou, H. The design of a $\mathrm{LiFePO}_{4} /$ carbon nanocomposite with a core-shell structure and its synthesis by an in situ polymerization restriction method. Angew. Chem. Int. Ed. 120, 75717575 (2008)

17. Wang, D. et al. Polymer wiring of insulating electrode materials: An approach to improve energy density of lithium-ion batteries. Electrochem. Commun. 11, 1350-1352 (2009).

18. Huang, Y. H., Park, K. S. \& Goodenough, J. B. Improving lithium batteries by tethering carbon-coated $\mathrm{LiFePO}_{4}$ to polypyrrole. J. Electrochem. Soc. 153, A2282-A2286 (2006).

19. Boyano, I. et al. Preparation of $\mathrm{C}-\mathrm{LiFePO}_{4} /$ polypyrrole lithium rechargeable cathode by consecutive potential steps electrodeposition. J. Power Sources 195, 5351-5359 (2010).

20. Wang, G. X. et al. An investigation of polypyrrole- $\mathrm{LiFePO}_{4}$ composite cathode materials for lithium-ion batteries. Electrochim. Acta 50, 4649-4654 (2005).

21. Vadivel Murugan, A., Muraliganth, T. \& Manthiram, A. Rapid microwavesolvothermal synthesis of phospho-olivine nanorods and their coating with a mixed conducting polymer for lithium ion batteries. Electrochem. Commun. 10, 903-906 (2008).

22. Lepage, D., Michot, C., Liang, G., Gauthier, M. \& Schougaard, S. B. A soft chemistry approach to coating of $\mathrm{LiFePO}_{4}$ with a conducting polymer. Angew. Chem. Int. Ed. 50, 6884-6887 (2011).

23. Wu, X., Jiang, L., Cao, F., Guo, Y. \& Wan, L. $\mathrm{LiFePO}_{4}$ nanoparticles embedded in a nanoporous carbon matrix: superior cathode material for electrochemical energy-storage devices. Adv. Mater. 21, 2710-2714 (2009).

24. Dominko, R. et al. The role of carbon black distribution in cathodes for Li ion batteries. J. Power Sources 119-121, 770-773 (2003).

25. McNeil, D. D. et al. Melt casting $\mathrm{LiFePO}_{4}$ : II. particle size reduction and electrochemical evaluation. J. Electrochem. Soc. 157, A463-A468 (2010).

26. Wang, D. et al. New solid-state synthesis routine and mechanism for $\mathrm{LiFePO}_{4}$ using LiF as lithium precursor. J. Solid State Chem. 177, 4582-4587 (2004).

27. Wang, D., Wu, X., Wang, Z. \& Chen, L. Cracking causing cyclic instability of $\mathrm{LiFePO}_{4}$ cathode material. J. Power Sources 140, 125-128 (2005).

28. Chehimi, M. M. (ed) Aryl Diazonium Salts: New Coupling Agents in Polymer and Surface Science (Wiley VCH Verlag GmbH \& Co. KGaA, 2012).

29. Peng, Z., Holm, A. H., Nielsen, L. T., Pedersen, S. U. \& Daasbjerg, K. Covalent sidewall functionalization of carbon nanotubes by a 'formation-degradation' approach. Chem. Mater. 20, 6068-6075 (2008).

30. Mirkhalaf, F., Paprotny, J. \& Schiffrin, D. J. Synthesis of metal nanoparticles stabilized by metal-carbon bonds. J. Am. Chem. Soc. 128, 7400-7401 (2006).

31. Adenier, A., Combellas, C., Kanoufi, F., Pinson, J. \& Podvorica, F. I. Formation of polyphenylene films on metal electrodes by electrochemical reduction of benzenediazonium salts. Chem. Mater. 18, 2021-2029 (2006).

32. Laurentius, L. et al. Diazonium-derived aryl films on gold nanoparticles: evidence for a carbon-gold covalent bond. ACS nano 5, 4219-4227 (2011).

33. Martin, P., Della Rocca, M. L., Anthore, A., Lafarge, P. \& Lacroix, J. C. Organic electrodes based on grafted oligothiophene units in ultrathin, large-area molecular junctions. J. Am. Chem. Soc. 134, 154-157 (2011).

34. Yan, H. et al. Activationless charge transport across 4.5 to $22 \mathrm{~nm}$ in molecular electronic junctions. Proc. Natl Acad. Sci. USA 110, 5326-5330 (2013).

35. Chen, Y., Freunberger, S. A., Peng, Z., Bardé, F. \& Bruce, P. G. Li-O 2 battery with a dimethylformamide electrolyte. J. Am. Chem. Soc. 134, 7952-7957 (2012).

36. Pinson, J. \& Podvorica, F. Attachment of organic layers to conductive or semiconductive surfaces by reduction of diazonium salts. Chem. Soc. Rev. 34, 429-439 (2005).

37. Madec, L. et al. Spontaneous grafting of diazonium salt. Structural examination at the grain agglomerate scale. J. Am. Chem. Soc. 135, 11614-11622 (2013).

38. Tang, Y. et al. $\mathrm{Li}_{2} \mathrm{NaV}_{2}\left(\mathrm{PO}_{4}\right)_{3}$ : A novel composite cathode material with high ratio of rhombohedral phase. J. Power Sources 227, 199-203 (2013).
39. Thotiyl, M. M. O. et al. A stable cathode for the aprotic $\mathrm{Li}^{-\mathrm{O}_{2}}$ battery. Nat. Mater. 12, 1050-1056 (2013).

40. Chen, Y., Freunberger, S. A., Peng, Z., Fontaine, O. \& Bruce, P. G. Charging a Li- $\mathrm{O}_{2}$ battery using a redox mediator. Nat. Chem. 5, 489-494 (2013).

41. Patai, S. (ed.) The Chemistry of Diazonium and Diazo groups (John Wiley and Sons, 1978)

42. Ait Salah, A. et al. FTIR features of lithium-iron phosphates as electrode materials for rechargeable lithium batteries. Spectrochim. Acta Part A Mol. Biomol. Spectrosc. 65, 1007-1013 (2006).

43. Burba, C. M. \& Frech, R. Raman and FTIR spectroscopic study of $\mathrm{Li}_{\mathrm{X}} \mathrm{FePO}_{4}$ $(0 \leq \mathrm{x} \leq 1)$. J. Electrochem. Soc. 151, A1032-A1038 (2004).

44. Li, C., Shi, G. \& Liang, Y. Electrochemical synthesis of free-standing poly(paraphenylene) films in composite electrolytes of boron trifluoride diethyl etherate and sulfuric acid. Synth. Met. 104, 113-117 (1999).

45. Gu, L. et al. Direct observation of lithium staging in partially delithiated $\mathrm{LiFePO}_{4}$ at atomic resolution. J. Am. Chem. Soc. 133, 4661-4663 (2011).

46. Peng, Z. et al. Micelle-assisted one-pot synthesis of water-soluble polyanilinegold composite particles. Langmuir 22, 10915-10918 (2006).

47. Shacklette, L. W. et al. Solid-state synthesis of highly conducting polyphenylene from crystalline oligomers. J. Chem. Phys. 73, 4098-4102 (1980).

48. Tang, K., Yu, X., Sun, J., Li, H. \& Huang, X. Kinetic analysis on $\mathrm{LiFePO}_{4}$ thin films by CV, GITT and EIS. Electrochim. Acta 56, 4869-4875 (2011).

49. Orikasa, Y. et al. Direct observation of a metastable crystal phase of $\mathrm{Li}_{x} \mathrm{FePO}_{4}$ under electrochemical phase transition. J. Am. Chem. Soc. 135, 5497-5500 (2012).

50. Liu, H. et al. Capturing metastable structures during high-rate cycling of $\mathrm{LiFePO}_{4}$ nanoparticle electrodes. Science 344, 1252817 (2014).

51. Fisher, C. A. J. \& Saiful Islam, M. Surface structures and crystal morphologies of $\mathrm{LiFePO}_{4}$ : relevance to electrochemical behavior. J. Mater. Chem. 18, 1209-1215 (2008).

52. Rodriguez, M. A., Van Benthem, M. H., Ingersoll, D., Vogel, S. C. \& Reiche, H. M. In situ analysis of $\mathrm{LiFePO}_{4}$ batteries: signal extraction by multivariate analysis. Powder Diffr. 25, 143-148 (2010).

53. Wang, L., Zhou, F., Meng, Y. S. \& Ceder, G. First-principles study of surface properties of $\mathrm{LiFePO}_{4}$ : Surface energy, structure, Wulff shape, and surface redox potential. Phys. Rev. B 76, 165435 (2007).

54. Jiang, D. E., Sumpter, B. G. \& Dai, S. Structure and bonding between an aryl group and metal surfaces. J. Am. Chem. Soc. 128, 6030-6031 (2006).

55. Moses, P. G., Mortensen, J. J., Lundqvist, B. I. \& Nørskov, J. K. Density functional study of the adsorption and van der Waals binding of aromatic and conjugated compounds on the basal plane of $\mathrm{MoS}_{2}$. J. Chem. Phys. 130, 104709 (2009).

56. Wang, J., Lv, C., Zhang, Y., Deng, L. \& Peng, Z. Polyphenylene wrapped sulfur/ multi-walled carbon nano-tubes via spontaneous grafting of diazonium salt for improved electrochemical performance of lithium-sulfur battery. Electrochim. Acta 165, 136-141 (2015).

57. Tachikawa, H. \& Shimizu, A. Diffusion dynamics of the $\mathrm{Li}^{+}$ion on a model surface of amorphous carbon: a direct molecular orbital dynamics study. $J$. Phys. Chem. B 109, 13255-13262 (2005).

58. Kresse, G. \& Joubert, D. From ultrasoft pseudopotentials to the projector augmented-wave method. Phys. Rev. B 59, 1758 (1999).

59. Dudarev, S. L., Botton, G. A., Savrasov, S. Y., Humphreys, C. J. \& Sutton, A. P Electron-energy-loss spectra and the structural stability of nickel oxide: An LSDA + U study. Phys. Rev. B 57, 1505 (1998).

60. Zhou, F., Cococcioni, M., Marianetti, C. A., Morgan, D. \& Ceder, G. Firstprinciples prediction of redox potentials in transition-metal compounds with LDA + U. Phys. Rev. B 70, 235121 (2004).

61. Tang, P. \& Holzwarth, N. A. W. Electronic structure of $\mathrm{FePO}_{4}, \mathrm{LiFePO}_{4}$, and related materials. Phys. Rev. B 68, 165107 (2003).

\section{Acknowledgements}

Z.P. is indebted to the 'Strategic Priority Research Program' of the Chinese Academy of Sciences (Grant No. XDA09010401), 'the Recruitment Program of Global Youth Experts' of China and the 'Science and Technology Development Program' of Jilin Province (Grant No. 20150623002TC). L.G. and E.W. appreciate the National Natural Science Foundation of China (Grant no. 21190040). Theoretical work at Louisiana State University (LSU) was in part supported by the US National Science Foundation (US-NSF) under the NSF EPSCoR Cooperative Agreement No. EPS-1003897 with additional support from the Louisiana Board of Regents, and used high-performance computing resources provided by LSU with support from the US-NSF.

\section{Author contributions}

Z.P. conceived and coordinated the research. L.G., Y.Z., J.W., Y.Z., S.M. and L.M. synthesized the diazonium salt; Y.B. and D.W. prepared LiFePO ${ }_{4}$; L.G. and Y.Z. performed reactions of $\mathrm{LiFePO}_{4}$ and diazonium salt and analysed the online MS, FTIR and PXRD measurements; W.C.M and Y.X. performed the theoretical calculations. Z.P., E.W 
and P.G.B. supervised the project. The manuscript was primarily written by Z.P., and all of the authors contributed to discussions and review.

\section{Additional information}

Supplementary Information accompanies this paper at http://www.nature.com/ naturecommunications

Competing financial interests: The authors declare no competing financial interests.

Reprints and permission information is available online at http://npg.nature.com/ reprintsandpermissions/
How to cite this article: Guo, L. et al. Unlocking the energy capabilities of micron-sized $\mathrm{LiFePO}_{4}$. Nat. Commun. 6:7898 doi: 10.1038/ncomms8898 (2015).

(c) (i) This work is licensed under a Creative Commons Attribution 4.0 International License. The images or other third party material in this article are included in the article's Creative Commons license, unless indicated otherwise in the credit line; if the material is not included under the Creative Commons license, users will need to obtain permission from the license holder to reproduce the material. To view a copy of this license, visit http://creativecommons.org/ licenses/by/4.0/ 